\section{Growth of Okra and Fruiting Pattern as Affected by Growth Regulators}

\author{
Lurline Marsh ${ }^{1}$ and Rufus Jones ${ }^{1}$ \\ Department of Agriculture, Natural Resources, and Home Economics, \\ Lincoln University, Jefferson City, MO 65101
}

\author{
Mark Ellersieck ${ }^{2}$ \\ Agriculture Experiment Station, University of Missouri, Columbia, \\ MO 65211
}

Additional index words. Abelmoschus esculentus, Alar, ethephon

\begin{abstract}
Growth and fruiting pattern of okra (Abelmoschus esculentus L. Moench) CV. Clemson Spineless as affected by the growth regulators Alar ( $N$-dimethylaminosuccinamic acid) and ethephon (2-chloroethyl phosphoric acid) were evaluated in field studies. Eight treatments consisting of Alar at 600, 1200, 2400, and $3600 \mu \mathrm{l} \cdot$ liter $^{-1}$ and ethephon at $200,400,600$, and $800 \mu \mathrm{l} \cdot \mathrm{liter}^{-1}$ and water control were applied as foliar sprays at the three- to four-true-leaf stage. Both growth regulators depressed shoot growth and leaf production. Ethephon reduced shoot length. Total fruit yield was not significantly affected by the treatments. However, ethephon-treated plants tended to produce fewer fruits and lagged behind Alar-treated plants and the control plants in Fruit production during the early harvests.
\end{abstract}

Okra is a malvaceous plant with lack of concentrated fruit set and, therefore, an extended fruiting period. Generally, an okra plant produces one flower in a different leaf axil each day (Tanda, 1985). The immature fruits are ready for fresh-market harvest between 4 and 7 days after anthesis (Kolhe and Chavan, 1964; Sistrunk et al., 1960). After the 7th day, fibrousness of the pods increases rapidly, rendering them inedible. The extended period of fruit set makes okra harvesting labor-intensive. For this reason, production has tended to move from the United States into countries with abundant and less-expensive labor (Robbins, 1982).

Fruit set of several crops has been improved using growth regulators. Some of these growth regulators include ethephon, which has been used on pepper (Cantliffe and Goodwin, 1975) and okra (Bisaria, 1979), Alar on okra (Godfrey-Sam-Aggrey and Ndoleh, 1978), Chlorflurenol on okra (Bhatnager and Sareen, 1983) and cucumber (Cantliffe et al., 1972), and PIX (1, 1-dimethyl-peperidinium chloride) and CCC (2chloroethyltrimethylammonium chloride) on okra (Zayed et al., 1985). Alar and ethephon are growth retardants and have varying effects on okra, depending on factors such as

\footnotetext{
Received for publication 21 Nov. 1988. Journal paper no. A6-206-88 of the Lincoln Univ. Agricultural Experiment Station. Trade names are mentioned with the understanding that no discrimination is intended and no endorsement by the authors or Lincoln Univ. is implied. Research supported in part by USDA-CSRS funds allocated to the Univ. Agricultural Experiment Station. The cost of publishing this paper was defrayed in part by the payment of page charges. Under postal regulations, this paper therefore must be hereby marked advertisement solely to indicate this fact.

${ }^{1}$ Assistant Professor.

${ }^{2}$ Assistant Professor, Agricultural Experiment Station Statistician.
}

\footnotetext{
NS Nonsignificant at $P=0.05$.
}

preparation, the herbicide $\alpha, \alpha, \alpha-$ (trifluralin) (Elanco, Indianapolis, Ind.), was applied at the rate of $0.6 \mathrm{~kg} \cdot \mathrm{ha}^{-1}$. Based on soil test recommendations, no fertilizer was applied. On 28 May 1986 and 15 May 1987, seed of 'Clemson Spineless' okra was planted $15 \mathrm{~cm}$ apart in rows $4.5 \mathrm{~m}$ long with $0.9 \mathrm{~m}$ between rows. Seedlings were thinned to 30 $\mathrm{cm}$ apart 1 week after emergence. The growth regulators were applied in aqueous solutions of Alar (Union Carbide, Research Triangle Park, N.C.) at 600, 1200, 2400, and 3600 $\mu \mathrm{l} \cdot$ liter $^{-1}$ and of ethephon (Uniroyal, Bethany, Corm.) at 200, 400, 600, and 800 $\mu \mathrm{l} \cdot$ liter $^{-1}$. One treatment was a deionized water control. The rate of spray application on the plants was $123 \mathrm{ml} \cdot \mathrm{m}^{-2}$ of ground area. Spraying was done with a backpack sprayer equipped with a $\mathrm{CO}_{2}$ tank. The treatments were applied to three-row plots 3 weeks after planting, when the plants were at the threeto four-true-leaf stage. This stage was selected because successful results were obtained when okra plants were sprayed after the second true-leaf stage (Bisaria, 1979; Godfrey-Sam-Aggrey and Ndoleh, 1978).

Data recorded included shoot length and number of branches, which were measured at the beginning of flowering and at final harvest. Number of leaves was recorded only at flowering, because senescence and abscission were underway by final harvest. Fruiting pattern was recorded by twice-weekly harvests during 32 days. The first harvest was 6 days after the first flowering. Twelve plants were harvested from the center row of the three-row plots. The fruits from each harvest were classified by size expressed as pod length, based on USDA standards for grades of okra (Grange, 1965); the classifications, in $\mathrm{cm}$, were: very small $<4.4$; small 4.4 to 8.9 ; medium $>8.9$ but $<12.7$, and large $>12.7$. Fruit weight and number for each size classification were determined for each harvest. The number of total fruits and multiple fruits ( 2 or more fruits per plant) were recorded each day from the four remaining plants in the center row. This was

Table 1. Effect of Alar and ethephon on growth of okra as determined at flowering and final harvest.

\begin{tabular}{|c|c|c|c|c|c|}
\hline \multirow{2}{*}{$\begin{array}{l}\text { Growth } \\
\text { regulator } \\
\left(\mu 1 \cdot \text { liter }^{-1}\right)\end{array}$} & \multicolumn{2}{|c|}{ Shoot length $(\mathrm{cm})$} & \multirow{2}{*}{$\begin{array}{c}\begin{array}{c}\text { No. of } \\
\text { leaves }\end{array} \\
\text { Flowering }\end{array}$} & \multicolumn{2}{|c|}{ No. of branches } \\
\hline & Flowering & Final & & Flowering & Final \\
\hline 0 & 49.3 & 121 & 26.3 & 4.2 & 5.0 \\
\hline \multicolumn{6}{|l|}{ Alar } \\
\hline 600 & 43.2 & 129 & 17.3 & 3.8 & 5.0 \\
\hline 1200 & 43.7 & 127 & 21.0 & 3.8 & 3.8 \\
\hline 2400 & 46.0 & 123 & 21.8 & 4.0 & 5.5 \\
\hline 3600 & 42.7 & 128 & 20.0 & 4.2 & 4.7 \\
\hline Linear & NS & NS & NS & NS & NS \\
\hline Quadratic & NS & NS & NS & NS & NS \\
\hline \multicolumn{6}{|l|}{ Ethephon } \\
\hline 200 & 45.7 & 100 & 19.8 & 3.8 & 4.5 \\
\hline 400 & 43.2 & 112 & 21.3 & 3.8 & 4.5 \\
\hline 600 & 40.5 & 117 & 21.3 & 3.8 & 4.5 \\
\hline 800 & 38.3 & 116 & 18.3 & 3.5 & 3.8 \\
\hline Linear & NS & NS & NS & NS & NS \\
\hline Quadratic & NS & NS & NS & NS & NS \\
\hline LSD 0.05 & 8.18 & 17.4 & 4.1 & 0.9 & 1.0 \\
\hline
\end{tabular}


Table 2. Effect of growth regulator on okra fruit yield of assorted sizes expressed as pod length.

\begin{tabular}{|c|c|c|c|c|c|c|c|c|c|c|}
\hline \multirow{3}{*}{$\begin{array}{l}\text { Growth } \\
\text { regulator } \\
\left(\mu \mathrm{l} \cdot \text { liter }^{-1}\right) \\
\end{array}$} & \multicolumn{10}{|c|}{ Fruit size } \\
\hline & \multicolumn{2}{|c|}{ Very small $^{z}$} & \multicolumn{3}{|c|}{ Small } & \multicolumn{2}{|c|}{ Medium } & \multicolumn{3}{|c|}{ Large } \\
\hline & $\begin{array}{c}\text { Wt } \\
\left(\mathrm{kg} \cdot \mathrm{ha} \mathrm{-}^{-1}, \text { hundreds }\right)\end{array}$ & $\begin{array}{c}\text { No. } \\
\text { (thousands/ha) }\end{array}$ & $\left(\mathrm{kg} \cdot \mathrm{ha} \mathrm{-}^{-1}\right.$, & $\begin{array}{l}\text { Wt } \\
1, \text { hundreds) }\end{array}$ & $\begin{array}{c}\text { No. } \\
\text { (thousands/ha) }\end{array}$ & $\begin{array}{c}\text { Wt } \\
\left(\mathrm{kg} \cdot \mathrm{ha}^{-1}, \text { hundreds }\right)\end{array}$ & $\begin{array}{c}\text { No. } \\
\text { (hundreds/ha) }\end{array}$ & (kg.ha- & $\begin{array}{c}\text { Wt } \\
-1 \text {, hundrcds) }\end{array}$ & $\begin{array}{c}\text { No. } \\
\text { (hundreds/ha) }\end{array}$ \\
\hline $\begin{array}{l}0 \\
\text { Alar } \\
\text { Alar }\end{array}$ & 14.6 & 25.1 & & 35.2 & 25.5 & 12.3 & 54.7 & & 12.4 & 31.9 \\
\hline 600 & 11.6 & 17.9 & & 30.3 & 23.6 & 10.8 & 50.6 & & 11.7 & 28.1 \\
\hline 1200 & 12.8 & 18.4 & & 40.0 & 34.6 & 12.2 & 72.2 & & 10.9 & 30.4 \\
\hline 2400 & 12.8 & 18.2 & & 40.2 & 28.3 & 9.7 & 48.7 & & 12.1 & 33.6 \\
\hline 3600 & 11.3 & 22.5 & & 35.1 & 27.5 & 11.9 & 51.8 & & 13.3 & 37.6 \\
\hline Linear & NS & NS & & NS & NS & NS & NS & & NS & NS \\
\hline Quadratic & NS & NS & & * & * & NS & NS & & NS & NS \\
\hline Ethephon & & & & & . & & & & & \\
\hline 200 & 13.2 & 19.5 & & 35.5 & 27.8 & 10.3 & 49.6 & & 6.7 & 18.0 \\
\hline 400 & 11.5 & 20.7 & & 30.4 & 22.0 & 9.6 & 43.2 & & 7.5 & 21.6 \\
\hline 600 & 12.7 & 18.7 & & 34.5 & 23.1 & 10.5 & 59.3 & & 7.2 & 19.8 \\
\hline 800 & 13.0 & 19.4 & & 32.4 & 22.4 & 12.7 & 59.6 & & 8.5 & 22.2 \\
\hline Linear & NS & NS & & NS & NS & -NS & NS & & NS & NS \\
\hline Quadratic & NS & NS & & NS & NS & NS & NS & & NS & NS \\
\hline LSD 0.05 & 4.1 & 6.8 & & 11.1 & 7.8 & 5.9 & 28.9 & & 7.2 & 18.5 \\
\hline
\end{tabular}

${ }^{2}$ Length: very small, $<4.4 \mathrm{~cm}$; small, 4.4 to $8.9 \mathrm{~cm}$; medium, $>8.9$ but $<12.7 \mathrm{~cm}$; large, $>12.7 \mathrm{~cm}$.

NS,*Nonsignificant or significant at $P=0.05$, respectively.

Table 3. Contrast effects of growth regulators on weight of okra produced over 10 harvests.

\begin{tabular}{lccc}
\hline \hline $\begin{array}{l}\text { Growth } \\
\text { regulators } \\
\left(\mu \text { l. liter }{ }^{-1}\right)\end{array}$ & \multicolumn{3}{c}{ Contrasts } \\
\cline { 2 - 4 } & Linear & Quadratic & Cubic \\
\hline 0 & $*$ & $*$ & $*$ \\
Alar & & & \\
600 & $*$ & NS & NS \\
1200 & $*$ & $*$ & $*$ \\
2400 & $*$ & $*$ & $*$ \\
3600 & $*$ & $*$ & $*$ \\
Ethephon & & & \\
200 & $*$ & $*$ & $*$ \\
400 & $*$ & NS & $*$ \\
600 & $*$ & NS & $*$ \\
800 & $*$ & NS & $*$ \\
\hline
\end{tabular}

NS, * Nonsignificant or significant at $P=0.05$, respectively.

Table 4. Contrast effects of growth regulators on number of okra produced over 10 harvests.

\begin{tabular}{lccc}
\hline \hline $\left.\begin{array}{l}\text { Growth } \\
\text { regulators } \\
(\mu \mathrm{l} \cdot \text { liter }\end{array}{ }^{-1}\right)$ & \multicolumn{3}{c}{ Contrasts } \\
\cline { 2 - 4 } & Linear & Quadratic & Cubic \\
\hline 0 & $*$ & $*$ & NS \\
Alar & & & \\
$\quad 600$ & $*$ & NS & NS \\
1200 & $*$ & $*$ & NS \\
2400 & $*$ & $*$ & NS \\
3600 & $*$ & $*$ & $*$ \\
Ethephon & & & \\
200 & $*$ & $*$ & $*$ \\
400 & $*$ & NS & $*$ \\
600 & $*$ & $*$ & $*$ \\
800 & $*$ & NS & $*$ \\
\hline
\end{tabular}

NS,*Nonsignificant or significant at $P=0.05$, respectively.

done by daily tagging of the open flowers on each plant for 32 days after the beginning of flowering. Tagged fruits were harvested 6 days after flowering. The number of multiple fruits per four plants per day was used to calculate the number of multiple fruits per plant per day.

The experimental design for both years was a randomized complete block with nine treatments and three replications. The data for both years are combined. The linear statistical model included Year, Rep within Year, Trt year $\times$ Treatment and Error. Linear, quadratic, and cubic responses were calculated to test for the effect of increasing levels of chemical. A LSD is calculated for testing control vs. chemical level of Alar vs. ethephon. The variable of fruit weight and number of fruit produced over harvest time was analyzed as a split plot. The main plot was a randomized complete block with the subplot including time of harvest and the interaction of treatment $\times$ harvest. Response contrasts were performed for each chemical over harvest.

Growth response of the okra plants to the plant growth regulators (PGR) was more pronounced at flowering than at the final stage of growth (Table 1). Both growth regulators tended to depress shoot length at flowering, but only the plants treated with $800 \mu$ lethephon/liter were significantly shorter than the control. Similar reductions in okra shoot length have been obtained by Zayed et al. (1985) using PIX, Terpal, and CCC; by Bisaria (1979) using ethephon, by Bhatnager and Sareen (1983) using Chlorflurenol, and by Godfrey-Sam-Aggrey and Ndoleh (1978) using Alar. By the final harvest, the Alartreated plants had increased their shoot length slightly beyond those of the control plants, while the ethephon-treated plants remained slightly shorter. These final shoot lengths were not significantly different from the control except at $200 \mu \mathrm{l}$ ethephon/liter. A previous study by Godfrey-Sam-Aggrey and Ndoleh (1978) showed that Alar did not significantly affect shoot length at later stages of growth. They suggested that the effect of Alar on height is reduced through dilution with advancement and growth.

The number of leaves at flowering was reduced by all levels of growth regulator treatment (Table 1). Number of branches on the treated plants was not different from the control. This was unexpected, for ethephon treatments have been reported to promote branching in other studies (Bisaria, 1979; Marsh and Jones, 1987). Perhaps this result is due to our single-treatment application compared to the multiple applications used in those previous studies (Bisaria; 1979; Marsh and Jones, 1987). In one of those studies (Marsh and Jones, 1987), the plants were stunted and yield was reduced. The increasing concentration of both plant growth regulators showed no significant trends for shoot length, number of leaves, or number of branches.

Neither total fruit weight nor number per unit area was influenced by the treatments; their respective ranges were 5900 to 7570 $\mathrm{kg} \cdot \mathrm{ha}^{-1}$ and 492,000 to $633,000 / \mathrm{ha}$. However, ethephon-treated plants tended to produce less cumulative fruit yield. A division of the total yield into fruits of different sizes showed that only the small fruits were significantly different among the eight treatments and control (Table 2). Alar at 1200 $\mu \mathrm{l} \cdot$ liter $^{-1}$ produced a significantly larger $^{2}$ number of small fruits than the control or some of the other treatments. Small fruits were the most frequently produced size, followed by the very small, then medium, and finally large, when harvested twice weekly.

The fruiting pattern of the plants harvested twice weekly during 10 harvests showed that Alar promoted early peaking in yield, while ethephon delayed it (Tables 3 and 4). All contrasts except that for Alar at $600 \mu \mathrm{l} \cdot$ liter $^{-1}$ showed significant linear and cubic response for okra weight (Table 3). The quadratic contrast for the three higher levels of Alar and the lowest level of ethephon was significant. This indicates that Afar caused the yield to peak early but to fall off at later harvest, as indicated by the significant quadratic contrast. However, the effect of ethephon was a slow, general increase in fruit weight that peaked in late harvests. The number of fruits produced showed similar response to the fruit weight except for a significant quadratic ef- 
feet for $600 \mu$ ethephon/liter and a nonsignificant effect for 1200 and $2400 \mu$ l Alar/ liter (Table 4).

Yields generally fluctuated with each harvest over the 10 harvests. This uneven harvest indicates the physiological state of the crop as it adjusts to the reduced source capacity and lower sink potentials (setting of new fruits). A large proportion of the yield was realized between harvests 6 and 10 and is partially due to increased daily production of total fruits and to multiple fruits per plant produced during the 18- to 32-day period (data not shown). On a few occasions in our study, we have observed as many as four fruits per day on a plant. The distribution of the major portion of yield during the 6 to 10 harvest period is consistent with the results of Akorada et al. (1986), who showed that $90 \%$ of the okra yield was produced within the first 5 weeks after the first harvest in the six early cultivars they studied.

Our results suggest that okra treated with a single application of Alar or ethephon at the concentrations used will not show any marked increase in fruit yield. Ethephon delayed fruit concentration until later harvests. Therefore, most of the fruit yield from ethephon-treated plants would be realized between harvests 6 and 10, while fruit yield from Alar-treated plants would have highest yield from harvests 4 through 10 . The results of these studies apply under the defined conditions of a single application to okra at the 3-to 4-leaf stage at concentrations of 200 to $800 \mu \mathrm{l} \cdot$ liter $^{-1}$ for ethephon or 600 to 3600 $\mu \mathrm{l} \cdot$ liter $^{-1}$ for Alar.

\section{Literature Cited}

Akorada, M.O., O.A. Anyim, and I.O.A. Emiola. 1986. Edible fruit productivity and harvest duration of okra in southern Nigeria. Trop. Agr. 63:110-112.

Bhatnagar, V.K. and R. Sareen. 1983. Influence of chlorflurenol on growth, sex expression and yield of corn. J. Maharashtra Agr. Univ. 8:280281.

Bisaria, A.K. 1979. Growth, sex expression and yield of okra treated with ethephon. Philippine Agr. 62:316-320.

Cantliffe, D.J., R.W. Robinson, and S. Shannon. 1972. Promotion of cucumber fruit set and development by chlorflurenol. HortScience 7:416418.

Cantliffe, D.J. and P. Goodwin. 1975. Red color enhancement of pepper fruits by multiple application of ethephon. J. Amer. Soc. Hort. Sci. 100:157-161.

Godfrey-Sam-Aggrey, W. and A.S. Ndoleh. 1978. Effects of alar on growth, flowering and yield of okra. Expt. Agr. 14:121-128.

Grange, G.R. 1965. United States standards for grades of okra for processing. USDA Food Safety and Quality Serv., Washington, D.C.

Kolhe, A.K.. and V.M. Chavan. 1964. Development of fruit, yielding capacity and influence of fruit maturity on the reproductive and vegetative behaviour in okra [Abelmoschus esculentus (L.) Moench] Indian J. Agr. Sci. 37:155166.

Marsh, L. and R. Jones. 1987. Effect of Ethrel on growth and fruiting of okra. HortScience 22(5): 1037 .

Robbins, R. 1982. Guide to okra production. Amer.
Veg. Grower 30(12):7-10.

Sistrunk, W.A., L.G. Jones, and J.C. Miller. 1960. Okra pod growth habits. Proc. Amer. Soc. Hort. Sci. 76:486-491.

Tanda, A.S. 1985. Floral biology, pollen dispersal and foraging behavior of honeybees in okra
(Abelmoschus esculentus). J. Apicultural Res. 24(4):225-227.

Zayed, E.A., A.I. El-Zawily, and S.A. Ibrahim. 1985. Growth, yield and chemical composition of okra plants as affected by some growth regulators. Angew. Bot. 59:199-208. 